\section{After Achilles}

Contrary to the view that using time as a diagnostic tool' is 'sloppy and idle' and that general practice has 'floundered' as a result of such unhelpful phrases, we consider that general practice has struggled to provide a robust evidence base to confirm or refute the value of time as a diagnostic strategy. ${ }^{1}$ One of the most important diagnostic tasks performed by the GP is discriminating between the majority of patients with minor, usually self-limiting, illness and the minority with serious disease. This was illustrated by a cohort of 2690 adults presenting with lower respiratory tract infections of whom $92 \%$ had recovered within 3 weeks and only $1.1 \%$ were hospitalised, none of whom died. ${ }^{2}$

In 2013 we proposed the hypothesis that the opportunity afforded by reviewing a patient over time substantially increases the total gain in certainty when making a diagnosis in low-prevalence settings (the 'time-efficiency principle') such as general practice. ${ }^{3}$ We argued that this approach safely and efficiently reduces the number of patients who need to be investigated in order to make a correct diagnosis for a single person. We predicted that the time-efficiency principle operates most effectively at low prevalence, typically up to $10 \%$. It has since been noted as a widely used strategy in primary care. The Lancet Oncology Commission on primary care noted that adequate diagnosis requires time for symptoms to evolve; emphasising that, although symptoms are common, cancer is rare. ${ }^{4}$ The time-efficiency principle has also been noted as an effective strategy for sifting common symptoms such as headache. ${ }^{5}$

What is required now is for the timeefficiency principle to be robustly evaluated, preferably by focusing on prospective studies. It is vital that we advocate the optimum number of consultations before referral rather than a simple view that quicker is always better. ${ }^{6}$ This may help us to understand why GPs continue to use these strategies and thus lessen overdiagnosis, despite government-led calls for more referrals and investigations. GPs need academic and College support to tolerate uncertainty appropriately, aided by their discerning and continuing use of time effectively and thus efficiently.
Greg Irving,

Clinical Lecturer in General Practice, University of Cambridge, Cambridge. E-mail: gi226lacam.ac.uk

John Holden,

GP, Garswood Surgery, Wigan.

\section{REFERENCES}

1 Jones R. After Achilles. Br J Gen Pract 2016; 66(644): 115. DOI:10.3399/bjgp16X683869. http:// bjgp.org/content/66/644/115

2 van Vugt SF, Butler CC, Hood K, et al. Predicting benign course and prolonged illness in lower respiratory tract infections: a 13 European country study. Fam Pract 2012; 29(2): 131-138. DOI: 10.1093/fampra/cmr081

3 Irving G. Holden J. The time-efficiency principle: time as the key diagnostic strategy in primary care. Fam Pract 2013; 30(4): 386-389.

4 Rubin G, Berendsen A, Crawford SM, et al. The expanding role of primary care in cancer control. Lancet Oncol 2015; 16(12): 1231-1272. DOI: 10.1016/S1470-2045(15)00205-3.

5 Bösner S, Hartel S, Diederich J, Baum E. Diagnosing headache in primary care: a qualitative study of GPs' approaches. Br J Gen Pract 2014; DOI: 10.3399/bjgp14X681325. http://bjgp.org/ content/64/626/e532.

6 Irving G. Holden J. Measures of promptness of cancer diagnosis in primary care. $\mathrm{Br} J$ Cancer 2013; 108(10): 2186. DOI: 10.1038/bjc.2013.193.

DOI: 10.3399/bjgp16X684913

\section{Fishing}

I am a rural GP but don't fish. ${ }^{1}$ As a GP principal for 24 years I would like to share my real-life experience. Last year I recorded 202 point-of-care CRP tests. In approximately two-thirds the test helped me exclude significant illness, and in about one-fifth it was useful to help identify serious illness.

\section{Exclusion of significant pathology}

In 80 cases a low CRP helped avoid giving antibiotics or other medications by answering specific questions, such as: 'Is this exacerbation of COPD infective? 'Is this vague abdominal tenderness an infective exacerbation of diverticulitis or just IBS?' And 'Is this unilateral headache and borderline tenderness temporal arteritis?'

\section{Avoiding admission}

In 14 cases a low CRP helped avoid admission, including a patient with vague confusion (? toxic) from pre-existing dementia, one with a headache (? infective ? migraine), one possible septic arthritis, and one possible appendicitis.

\section{Providing reassurance}

In 40 cases, a normal test reinforced reassurance, reducing anxiety and the need for follow-up.

\section{Confirmation of serious illness}

In 44 cases a high CRP helped identify significant illness: 23 patients were given antibiotics and 21 admitted to hospital, including two pneumonias, an appendix abscess, a staphylococcal infected dialysis line (no signs), UTI presenting with ataxia, and a 96-year-old with no signs, no fever, with pneumonia.

There are limitations to any test, including point-of-care CRP, and it should never be a substitute for clinical judgement. However, as GPs we have a unique role in early diagnosis of disease and, from my experience, I maintain that this test can be a useful adjunct in the GP's armoury; there is surely scope for further research to examine exactly where it fits in.

Oliver Penney,

GP, Weobley Surgery, Hereford.

E-mail: doktaoliagmail.com

\section{REFERENCE}

1. Watson J, de Salis I, Hamilton W, Salisbury C. I'm fishing really' - inflammatory marker testing in primary care: a qualitative study. Br J Gen Pract; DOI: 10.3399/bjgp16X683857. http://bjgp.org/ content/66/644/e200.

DOI: 10.3399/bjgp16X684937

\section{Correction}

In the March 2016 article by Lim AWW et al. Performance characteristics of visualising the cervix in symptomatic young females: a review of primary care records in females with and without cervical cancer. Br J Gen Pract 2016; DOI: 10.3399/ bjgp16X683833, http://bjgp.org/content/66/644/e189, the Results section stated, 'Fifty-two per cent (56 of 107) of young females with cervical cancer had gynaecological symptoms ... Of these, 39\% (22 of 57) had a documented cervical examination.' This number should have been 22 of 56 , not 22 of 57 . We apologise for this error. The online version has been corrected.

DOI: 10.3399/bjgp16X684829 